\title{
Association of fruit and vegetable intake with cardiovascular risk factors in urban south Indians
}

\author{
Ganesan Radhika, Vasudevan Sudha, Rangaswamy Mohan Sathya, Anbazhagan Ganesan \\ and Viswanathan Mohan* \\ Madras Diabetes Research Foundation and Dr Mohan's Diabetes Specialities Centre, 4 Conran Smith Road, Gopalapuram, \\ Chennai, India
}

(Received 17 January 2007 - Revised 5 June 2007 - Accepted 25 June 2007)

The study examines the relationship between fruit and vegetable intake $(\mathrm{g} / \mathrm{d})$ and CVD risk factors in urban south Indians. The study population comprised of 983 individuals aged $\geq 20$ years selected from the Chennai Urban Rural Epidemiological Study (CURES), a population-based crosssectional study on a representative population of Chennai in southern India. Fruit and vegetable intake (g/d) was measured using a validated semiquantitative FFQ. Linear regression analysis revealed that after adjusting for potential confounders such as age, sex, smoking, alcohol, BMI and total energy intake, the highest quartile of fruit and vegetable intake $(\mathrm{g} / \mathrm{d})$ showed a significant inverse association with systolic blood pressure $(\beta=-2.6(95 \%$ CI $-5.92,-1.02) \mathrm{mmHg} ; P=0.027)$, BMI $\left(\beta=-2.3(95 \% \mathrm{CI}-2.96,-1.57) \mathrm{kg} / \mathrm{m}^{2} ; P<0.0001\right)$, waist circumference $(\beta=-2.6(95 \% \mathrm{CI}-3.69,-1.46) \mathrm{cm} ; P<0.0001)$, total cholesterol $(\beta=-50(95 \% \mathrm{CI}-113.9,-13.6) \mathrm{mg} / \mathrm{l} ; P=0.017)$ and LDL-cholesterol concentration $(\beta=-55(95 \% \mathrm{CI}-110 \cdot 8,-11 \cdot 1) \mathrm{mg} / \mathrm{l} ; P=0.039)$ when compared with the lowest quartile. A higher intake of fruit and vegetables explained $48 \%$ of the protective effect against CVD risk factors. Increased intake of fruits and vegetables could play a protective role against CVD in Asian Indians who have high rates of premature coronary artery disease.

Fruit and vegetables: Cardiovascular risk factors: Non-communicable diseases: Diabetes: Asian Indians

Although CVD was earlier more prevalent in developed countries, its burden is now higher in developing countries ${ }^{1}$. According to recent projections, by the year 2020, 6.4 million deaths due to CVD could occur in developing countries in the age group of 30-69 years ${ }^{2}$. Asian Indians are known to have a greater susceptibility to type 2 diabetes and premature coronary artery disease compared with Europeans ${ }^{1,3,4}$. Like other developing countries in transition, increased life expectancy, urbanisation, changes in dietary patterns from 'traditional' to 'Western' and physical inactivity due to increased affluence are some of the important contributors to the rapidly rising prevalence of cardiovascular risk factors in urban Indians ${ }^{5}$.

Diet has long been linked to the development of obesity, diabetes and $\mathrm{CVD}^{6}$ and dietary modification is one of the cornerstones of chronic disease prevention. Examination of single nutrients in relation to CVD risk may ignore the biochemical complexity of whole foods. In addition, dietary advice becomes easier to understand and follow if provided in terms of whole foods. The beneficial effect of diets rich in fruits and vegetables has been well recognised for the prevention of chronic diseases, especially CVD, as they contain substantial amounts of nutrients such as folate, antioxidant vitamins, $\mathrm{K}$ and dietary fibre ${ }^{7-9}$.
The World Health Report ${ }^{10}$ estimates that low fruit and vegetable intake contributes to approximately 2.7 million deaths $(4.9 \%)$ per year from chronic diseases and causes about $31 \%$ IHD and $11 \%$ stroke worldwide. Indeed low fruit and vegetable intake is ranked as the seventh main risk factor among causes of disability-adjusted life-years in developing countries with low mortality.

Several studies in the West have reported on the beneficial effect of fruit and vegetable consumption with respect to CVD risk ${ }^{11-13}$. There is an urgent need for such data from India where rapid nutritional transition is ongoing due to urbanisation and globalisation leading to increasing levels of potentially reversible CVD risk factors ${ }^{1}$. Furthermore, a clear understanding of the relationship between fruit and vegetable intake and CVD risk could also provide a more direct scientific basis for practical dietary guidelines for the prevention of CVD. Therefore, in the present crosssectional study, we sought to evaluate the association of fruit and vegetable intake with cardiovascular risk factors such as obesity, hypertension, fasting plasma glucose and dyslipidaemia in urban Asian Indians in southern India.

Abbreviation: CURES, Chennai Urban Rural Epidemiological Study.

* Corresponding author: Dr V. Mohan, fax +91 442835 0935, email drmohans@ vsnl.net 


\section{Materials and methods}

\section{Sampling}

Study subjects were recruited from the Chennai Urban Rural Epidemiology Study (CURES), an ongoing epidemiological study conducted on a representative population of Chennai city (formerly Madras) in southern India with a population of about 5 million individuals. The methodology of the study has been published elsewhere ${ }^{14}$. Our website http://www. drmohansdiabetes.com (under the link 'publications') provides details of the sampling frame. Briefly, the city of Chennai is divided into 155 corporation wards representing a socio-economically diverse group. In Phase 1 of CURES, individuals from fourty-six corporation wards were screened by a systematic sampling technique. The sample distribution in each ward within these zones is based on the proportion of their population in that particular zone. A probabilistic proportionate sampling was adopted to select the number of individuals seen in each ward. Furthermore, within each ward, every third lane or road, following the right-hand rule, was surveyed. A total of 26001 individuals aged $\geq 20$ years were screened.

Phase 2 of CURES deals with studies on the prevalence of microvascular and macrovascular complications of diabetes. Phases 1 and 2 are not discussed further in the present article.

In phase 3 of CURES, every tenth subject recruited in phase 1 ( $n$ 2600) was invited to our centre for detailed anthropometric measurements and biochemical tests and every alternate individual from the group $(n$ 1300) was invited for detailed dietary studies. Of these, 1143 subjects participated in the present study (response rate $87.9 \%$ (1143 out of 1300 individuals)). This sample is thus representative of the Chennai population. Subjects with self-reported history of diabetes or hypertension or CVD or on drug therapy for dyslipidaemia were excluded ( $n$ 160). The remaining 983 subjects were included in the present study.

All study subjects underwent an oral glucose tolerance test using a glucose load of $75 \mathrm{~g}$, except self-reported diabetic subjects, for whom fasting venous plasma glucose was measured. The fasting blood sample was taken after ensuring $8 \mathrm{~h}$ overnight fasting, for estimation of plasma glucose and serum lipids using a Hitachi 912 Autoanalyser (Roche Diagnostics GmbH, Mannheim, Germany) utilising kits supplied by Boehringer Mannheim (Mannheim, Germany). Anthropometric measurements including weight, height, waist and hip measurements were obtained using standardised techniques ${ }^{14}$. Blood pressure was recorded in the right upper limb in sitting position to the nearest $2 \mathrm{mmHg}$ using an $\mathrm{Hg}$ sphygmomanometer (Diamond Deluxe BP apparatus; Industrial Electronic \& Allied Products, Pune, India). Two readings were taken 5 min apart, and the mean of two was taken as the blood pressure. Demographic and socio-economic characteristics, medical history, medications, family history of diseases, smoking status (current smokers: yes or no) and alcohol consumption (current drinker: yes or no) were also obtained ${ }^{14}$. The institutional ethical committee approval was obtained and informed consent was obtained from all study subjects.

\section{Definitions}

Newly diagnosed diabetes. Diagnosis of "newly detected diabetic subjects' was based on WHO consulting group criteria, i.e. fasting plasma glucose $\geq 1260 \mathrm{mg} / \mathrm{l}(7 \mathrm{mmol} / \mathrm{l})$ and/or $2 \mathrm{~h}$ post-load plasma glucose $\geq 2000 \mathrm{mg} / 1(\geq 11 \cdot 1 \mathrm{mmol} / \mathrm{l})^{15}$.

Newly diagnosed hypertension. Hypertension was diagnosed based on systolic blood pressure $\geq 130 \mathrm{mmHg}$ or diastolic blood pressure of $\geq 85 \mathrm{mmHg}^{16}$.

Dyslipidaemia. This was defined using National Cholesterol Education Program Adult Treatment Panel ${ }^{17}$ guidelines as follows.

Hypercholesterolaemia was diagnosed if serum cholesterol levels were $\geq 2000 \mathrm{mg} / \mathrm{l}$ ( $\geq 5 \cdot 2 \mathrm{mmol} / \mathrm{l})$.

Hypertriacylglycerolaemia was diagnosed if serum TAG levels were $\geq 1500 \mathrm{mg} / \mathrm{l}(\geq 1.7 \mathrm{mmol} / \mathrm{l})$.

Low high-density-lipoprotein-cholesterol was diagnosed if HDL-cholesterol levels were $<400 \mathrm{mg} / \mathrm{l}$ for men and $<500 \mathrm{mg} / \mathrm{l}$ for women.

High low-density-lipoprotein-cholesterol was diagnosed if LDL-cholesterol levels were $\geq 1300 \mathrm{mg} / \mathrm{l}$.

\section{Dietary assessment}

Usual dietary intake was assessed by using a validated interviewer-administered semi-quantitative FFQ (meal-based) ${ }^{18}$. The nutritionists responsible for the data collection were well trained in the methodology to be used before fieldwork was started. Data were collected by one-to-one interview after obtaining informed consent. The FFQ took about 2030 min to complete. This FFQ contains 222 items that included commonly available and eaten fruits (twenty fruits including both citrus and non-citrus variety) and twenty-five vegetables in the form of both raw and cooked foods including cruciferous (cabbage, broccoli, cauliflower), dark yellow (excluded tubers), green leafy vegetables (amaranth, spinach, palak, drumstick leaves (Moringa oleifera), mint, coriander) and other vegetables (egg plant, mixed vegetables, drumstick, mushrooms, ladies' fingers (okra), knol-knol, chow-chow, gourd varieties). Data on the seasonal availability of fruits and vegetables were obtained from local wholesale vendors ${ }^{18}$. These values were used to convert reported seasonal intake into average intake throughout the year (For example, mangoes are seasonal and are available for the period of 3 months. Suppose if the respondent reported consuming one medium-size mango once-weekly, the nutritionist will convert it to yearly as twelve mangoes (with 4 weeks in each month).)

For each fruit or vegetable, a usual serving size was specified and the individuals were asked to estimate the usual frequency (number of times per d, week, month or year, or never) on average, during the previous year they had consumed that amount. Common household measures such as household cups, bowls, ladles, spoons (for the cooked foods such as vegetables), wedges (to estimate slices of cakes and fruits), circles of different diameter (to estimate the portion size of foods such as paratas or chapatis) and a visual atlas of different sizes of fruits (small, medium, large) were shown to assist the individuals in the estimating process. Frequencies and serving size of the individual food items were converted to average daily intake $(\mathrm{g} / \mathrm{d})$ of each fruit and vegetable item for each subject. The average daily intakes of individual foods were summed to compute total fruit and vegetable intake $(\mathrm{g} / \mathrm{d})$. Information on total energy was obtained using the same FFQ. A detailed description of the reproducibility and validity of the FFQ has been published elsewhere ${ }^{18}$. Validity of the 
FFQ has been documented by comparisons with multiple $24 \mathrm{~h}$ recalls collected at 2-monthly intervals for a period of 1 year covering all four seasons. This included four weekdays and two weekends to capture variability in weekend $v$. weekday food intakes. The energy-adjusted deattenuated Pearson correlation coefficients for the response to the 222-item questionnaire, for fruits and vegetables from the questionnaire compared with six $24 \mathrm{~h}$ recalls, averaged 0.28 .

Reported individual food items were converted to average daily intake of each fruit and vegetable item for each participant using an in-house EpiNu India ${ }^{\circledR}$ database and software (Nutritional Epidemiology, Food and Nutrient database, version 1.0), developed and launched by the Department of Nutrition and Dietetics Research of Madras Diabetes Research Foundation. This database contains comprehensive data for 1500 recipes (both commercial and non-commercial) and sixty nutrients. The average daily intakes of individual food items were combined to compute total fruit and vegetable intake.

\section{Statistical analysis}

All analyses were conducted using the statistical software package SPSS (version 10.0; SPSS, Inc., Chicago, IL, USA). Subjects were divided into quartiles of fruit and vegetable intake $(\mathrm{g} / \mathrm{d})$. The mean of each was reported and compared for the descriptive characteristic. Values are expressed as means and standard deviations. One-way ANOVA or Student's $t$ test as appropriate was used to compare continues variables, and the $\chi^{2}$ test was used to compare the proportions among groups. To investigate whether the clustering of CVD risk factors was significantly related to fruit and vegetable intake, we computed $Z$ scores by sex for all nine risk factor variables (systolic blood pressure, diastolic blood pressure, BMI, waist circumference, fasting plasma glucose, total serum cholesterol, TAG, HDL-cholesterol and LDL-cholesterol). $Z$ scores were computed as the number of SD units from the sample mean, i.e. $Z=(($ individual value - the sexspecific mean value)/sex-specific SD). The HDL-cholesterol $Z$ score was multiplied by -1 to indicate higher cardiovascular risk with increasing value. The sum of all $Z$ scores indicates the cluster of cardiovascular risk factors. Regression analysis was carried out using cardiovascular risk factors as dependent variables and the first and fourth quartile of fruit and vegetable intake $(\mathrm{g} / \mathrm{d})$ as the independent variable with adjustment for potential confounders such as age (years), sex (dichotomous), BMI (continuous variable), current smoking (yes or no), alcohol (yes or no) and total energy intake (kJ). All tests of significance were two-tailed and a $P$ value of $<0.05$ was considered significant.

\section{Results}

The baseline characteristics of the study participants by sex are presented in Table 1. The ages of the men and the women were 40.2 (SD 12.6) and 38.8 (SD 11.5) years respectively. Men had significantly lower BMI $(P=0 \cdot 003)$ and HDLcholesterol concentration $(P<0.0001)$ but higher systolic blood pressure $(P=0.009)$, diastolic blood pressure $(P<0.0001)$, waist circumference $(P<0.0001)$, fasting blood sugar $(P=0.055)$ and serum TAG $(P<0.0001)$ compared with women. Similarly men had higher prevalence of hypertension $(P=0.023)$ and dyslipidaemia $(P<0 \cdot 0001)$ than women. No significant mean differences were observed in the fruit and vegetable intake $(\mathrm{g} / \mathrm{d})$ between the sexes. Fruit and vegetable intake did not differ between non-vegetarians

Table 1. General and clinical characteristics of the representative population of 983 urban subjects (Mean values and standard deviations or proportions)

\begin{tabular}{|c|c|c|c|c|c|}
\hline \multirow[b]{2}{*}{ Variables } & \multicolumn{2}{|c|}{ Males $(n$ 455) } & \multicolumn{2}{|c|}{ Females ( $n$ 528) } & \multirow[b]{2}{*}{$P^{*}$} \\
\hline & Mean & SD & Mean & SD & \\
\hline Participants (\%) & \multicolumn{2}{|c|}{$46 \cdot 3$} & \multicolumn{2}{|c|}{$53 \cdot 7$} & - \\
\hline Age (years) & $40 \cdot 2$ & $12 \cdot 6$ & $38 \cdot 8$ & 11.5 & NS \\
\hline BMI $\left(\mathrm{kg} / \mathrm{m}^{2}\right)$ & $22 \cdot 8$ & $3 \cdot 6$ & $23 \cdot 4$ & $4 \cdot 1$ & 0.003 \\
\hline Systolic blood pressure (mmHg) & $118 \cdot 7$ & $16 \cdot 6$ & $115 \cdot 8$ & $18 \cdot 2$ & 0.009 \\
\hline Diastolic blood pressure (mmHg) & 74.5 & $11 \cdot 4$ & $71 \cdot 8$ & $11 \cdot 2$ & $<0.0001$ \\
\hline Waist circumference $(\mathrm{cm})$ & $84 \cdot 7$ & $11 \cdot 0$ & $81 \cdot 0$ & $10 \cdot 7$ & $<0.0001$ \\
\hline Fasting blood glucose (mg/l) & 914 & 271 & 883 & 234 & 0.055 \\
\hline Serum total cholesterol (mg/l) & 1766 & 366 & 1789 & 373 & NS \\
\hline Serum TAG $(\mathrm{mg} / \mathrm{l})$ & 1333 & 849 & 1127 & 690 & $<0.0001$ \\
\hline Serum HDL-cholesterol (mg/l) & 400 & 103 & 447 & 94 & $<0.0001$ \\
\hline Serum LDL-cholesterol (mg/l) & 1099 & 307 & 1117 & 322 & NS \\
\hline Prevalence of newly diagnosed diabetes (\%) & \multicolumn{2}{|c|}{$9 \cdot 2$} & \multicolumn{2}{|c|}{$6 \cdot 8$} & NS \\
\hline Prevalence of newly diagnosed hypertension (\%) & \multicolumn{2}{|c|}{$30 \cdot 1$} & \multicolumn{2}{|c|}{$24 \cdot 2$} & 0.023 \\
\hline Prevalence of newly diagnosed dyslipidaemia (\%) & \multicolumn{2}{|c|}{$91 \cdot 2$} & \multicolumn{2}{|c|}{$55 \cdot 7$} & $<0.0001$ \\
\hline Fruits and vegetables $(\mathrm{g} / \mathrm{d})$ & 259.6 & $103 \cdot 8$ & 270.4 & $126 \cdot 2$ & NS \\
\hline Total energy $(\mathrm{kJ} / \mathrm{d})$ & 11159 & 2573 & 9887 & 2201 & $<0.0001$ \\
\hline Total energy (kcal/d) & 2667 & 615 & 2363 & 526 & $<0.0001$ \\
\hline Current cigarette smoking (\%) & \multicolumn{2}{|c|}{$43 \cdot 7$} & \multicolumn{2}{|c|}{0} & $<0.0001$ \\
\hline Alcohol consumption (\%) & \multicolumn{2}{|c|}{$51 \cdot 2$} & \multicolumn{2}{|c|}{0.6} & $<0.0001$ \\
\hline CVD risk factors ( $Z$ score) $\dagger$ & 0.25 & 4.8 & -0.23 & $4 \cdot 7$ & NS \\
\hline
\end{tabular}

* For continuous characteristics, performed using Student's $t$ test. For categorical tests, the $\chi^{2}$ test for trend was used.

†CVD risk factor score was calculated as the sum of $Z$ scores for systolic blood pressure, diastolic blood pressure, waist circumference, BMI, fasting plasma glucose, total cholesterol, TAG, LDL-cholesterol and HDL-cholesterol. 
( $n$ 897; 263 (SD 111.1) g/d) and vegetarians including ovovegetarians ( $n$ 86;278.7 (SD 143.5) $\mathrm{g} / \mathrm{d} ; P=0.357$ ). The cardiovascular risk factor score was higher in men $(0 \cdot 25$ (SD $4 \cdot 8)$ ) compared with women (-0.23 (SD 4.7)).

\section{Fruit and vegetable consumption}

The clinical characteristics of the study participants by quartiles of fruit and vegetables are presented in Table 2. Intake of fruit and vegetables ranged from $141 \mathrm{~g} / \mathrm{d}$ in the lowest quartile to $418 \mathrm{~g} / \mathrm{d}$ in the highest quartile. A higher intake of fruit and vegetables was associated with younger age ( $P$ for trend $<0.001$ ), lower prevalence of hypertension ( $P$ for trend $=0.005)$ and dyslipidaemia $(P$ for trend $<0 \cdot 0001)$. Systolic blood pressure $(P$ for trend $<0.001)$, diastolic blood pressure ( $P$ for trend $=0 \cdot 002)$, BMI $(P$ for trend $=0.004)$, serum cholesterol ( $P$ for trend $<0.001$ ), serum LDL-cholesterol ( $P$ for trend $<0.0001)$ and waist circumference $(P$ for trend $<0.0001)$ were significantly lower in those in the higher quartiles of fruit and vegetable intake. CVD risk score ( $P$ for trend $<0.0001)$ was inversely related to higher fruit and vegetable intake $(\mathrm{g} / \mathrm{d})$.

\section{Association between fruit and vegetable intake with} cardiovascular risk factors

In a regression analysis model, we observed a significant inverse association in cardiovascular risk factors and fruit and vegetable intake $(\mathrm{g} / \mathrm{d})$ (Table 3 ). Higher intake of energyadjusted fruit and vegetable intake showed an significant inverse association with systolic blood pressure $(\beta=-5.4$ (95\% CI $-8.89,-1.944) \mathrm{mmHg} ; P=0.002)$, diastolic blood pressure $(\beta=-3.4 \quad(95 \%$ CI $-5.86,-1.483) \mathrm{mmHg}$;
$P<0.0001)$, BMI $\left(\beta=-2 \cdot 0(95 \%\right.$ CI $-2.74,-1.32) \mathrm{kg} / \mathrm{m}^{2}$; $P<0.0001)$, waist circumference $(\beta=-7.9$ (95\% CI -9.87 , $-5.96) \mathrm{cm} ; P<0.0001)$, serum total cholesterol $(\beta=-77$ (95\% CI $-140 \cdot 3,-13 \cdot 0) \mathrm{mg} / \mathrm{l} ; P=0 \cdot 019)$, LDL-cholesterol $(\beta=-79(95 \%$ CI $-134.1,-24.8) \mathrm{mg} / \mathrm{l} ; P=0.004)$ and HDL-cholesterol $(\beta=29 \quad(95 \%$ CI $10 \cdot 8, \quad 40 \cdot 7) \quad \mathrm{mg} / \mathrm{l}$; $P=0.002)$ when compared with the lowest quartile (model 1). Adjusting for age and sex (model 2) did not alter the significant association for systolic blood pressure $(\beta=-4.5$ (95\% CI $-7.76,-1.29) \mathrm{mmHg} ; P=0.006)$, diastolic blood pressure $(\beta=-3.2$ (95\% CI $-5.33,-1.09) \mathrm{mmHg} ; P=0.003)$, BMI $\left(\beta=-2.3(95 \%\right.$ CI $\left.-2.91,-1.52) \mathrm{kg} / \mathrm{m}^{2} ; P<0.0001\right)$, waist circumference $(\beta=-7.6(95 \%$ CI $-9.58,-5.69)$ $\mathrm{cm} ; P<0 \cdot 0001)$, serum total cholesterol $(\beta=-73(95 \% \mathrm{CI}$ $-134.5,-11.4) \mathrm{mg} / \mathrm{l} ; P=0 \cdot 020)$, HDL-cholesterol $(\beta=26$ (95\% CI 8.8, 44.0) $\mathrm{mg} / \mathrm{l} ; P=0.003)$ and LDL-cholesterol $(\beta=-77$ (95\% CI $-130 \cdot 6,-22.5) \mathrm{mg} / \mathrm{l} ; P=0 \cdot 006)$. Further, introducing smoking and alcohol (model 3 ) into the model did not alter the results. Though there was a strong association for consumption of fruit and vegetables with diastolic blood pressure this became insignificant after adjustment for BMI (model 4) but a significant inverse association persisted for systolic blood pressure $(\beta=-2.6$ (95\% CI $-5.92,-1.02) \mathrm{mmHg}$; $P=0.027)$, waist circumference $(\beta=-2.6(95 \%$ CI -3.69 , $-1.46) \mathrm{cm} ; P<0.0001)$, serum total cholesterol $(\beta=-50$ (95\% CI $-113.9,-13.6) \mathrm{mg} / \mathrm{l} ; P=0.017)$ and LDL-cholesterol $(\beta=-55(95 \% \mathrm{CI}-110 \cdot 8,-11 \cdot 1) \mathrm{mg} / \mathrm{l} ; P=0.039)$ with fruit and vegetable intake $(\mathrm{g} / \mathrm{d})$. Higher fruit and vegetable intake $(\mathrm{g} / \mathrm{d})$ was inversely related to the CVD risk score $(\beta=-1.0$ (95\% CI $-1.74,-0.32) ; P=0.004)$ even after adjusting for all the confounding factors. The highest quartile of fruit and vegetables explained $48 \%$ of the protective effect against CVD risk factors compared with the lowest quartile.

Table 2. Description of cardiovascular risk factors according to quartiles $(Q)$ of fruit and vegetable intake $(\mathrm{g} / \mathrm{d})$ of 983 subjects (Mean values and standard deviations or proportions)

Fruit and vegetable intake in quartiles $(\mathrm{g} / \mathrm{d})$

\begin{tabular}{|c|c|c|c|c|c|c|c|c|c|}
\hline \multirow[b]{2}{*}{ Variables } & & & & & & & \multirow[b]{2}{*}{$P$ for trend ${ }^{*}$} \\
\hline & Mean & SD & Mean & SD & Mean & SD & Mean & SD & \\
\hline Quartile range for intake $(\mathrm{g} / \mathrm{d})$ & \multicolumn{2}{|c|}{$30-186$} & \multicolumn{2}{|c|}{$186-248$} & \multicolumn{2}{|c|}{$248-327$} & \multicolumn{2}{|c|}{$327-1026$} & _ \\
\hline Mean quartile intake $(\mathrm{g} / \mathrm{d})$ & 141 & - & 215 & - & 287 & - & 418 & - & - \\
\hline Subjects $(n)$ & \multicolumn{2}{|c|}{245} & \multicolumn{2}{|c|}{246} & \multicolumn{2}{|c|}{246} & \multicolumn{2}{|c|}{246} & - \\
\hline Age (years) & 41.8 & 13.5 & 39.6 & 11.9 & 38.2 & $11 \cdot 2$ & 38.5 & $11 \cdot 2$ & $<0.001$ \\
\hline $\mathrm{BMI}\left(\mathrm{kg} / \mathrm{m}^{2}\right)$ & 23.4 & 4.1 & $23 \cdot 3$ & 3.8 & $22 \cdot 8$ & $3 . \overline{6}$ & 22.5 & 4.2 & 0.004 \\
\hline Smoking (\%) & \multicolumn{2}{|c|}{$21 \cdot 2$} & \multicolumn{2}{|c|}{$23 \cdot 2$} & \multicolumn{2}{|c|}{$21 \cdot 1$} & \multicolumn{2}{|c|}{15.9} & 0.114 \\
\hline Alcohol (\%) & \multicolumn{2}{|c|}{20.4} & \multicolumn{2}{|c|}{32.5} & \multicolumn{2}{|c|}{$21 \cdot 1$} & \multicolumn{2}{|c|}{22} & 0.577 \\
\hline Systolic blood pressure $(\mathrm{mmHg})$ & $120 \cdot 4$ & $20 \cdot 8$ & 117.5 & $16 \cdot 1$ & $115 \cdot 1$ & $16 \cdot 1$ & $115 \cdot 5$ & $16 \cdot 3$ & $<0.001$ \\
\hline Diastolic blood pressure $(\mathrm{mmHg})$ & 74.6 & $12 \cdot 2$ & 73.6 & $11 \cdot 2$ & $72 \cdot 4$ & $10 \cdot 6$ & 71.7 & 11.4 & 0.002 \\
\hline Waist circumference $(\mathrm{cm})$ & 84.8 & $10 \cdot 7$ & 84.4 & $10 \cdot 1$ & $81 \cdot 7$ & $10 \cdot 3$ & 80 & 12 & $<0.0001$ \\
\hline Fasting blood glucose $(\mathrm{mg} / \mathrm{l})$ & 919 & 304 & 914 & 269 & 871 & 166 & 887 & 249 & 0.058 \\
\hline Serum total cholesterol $(\mathrm{mg} / \mathrm{l})$ & 1814 & 349 & 1824 & 425 & 1750 & 357 & 1724 & 336 & 0.001 \\
\hline Serum TAG $(\mathrm{mg} / \mathrm{l})$ & 1232 & 673 & 1306 & 821 & 1178 & 792 & 1173 & 798 & $0 \cdot 168$ \\
\hline Serum HDL-cholesterol & 418 & 96 & 423 & 96 & 428 & 109 & 432 & 104 & 0.116 \\
\hline Serum LDL-cholesterol (mg/l) & 1150 & 292 & 1140 & 357 & 1086 & 305 & 1058 & 295 & $<0.0001$ \\
\hline Newly diagnosed diabetes (\%) & \multicolumn{2}{|c|}{9} & \multicolumn{2}{|c|}{9.8} & \multicolumn{2}{|c|}{$4 \cdot 1$} & & 0.311 \\
\hline Newly diagnosed hypertension (\%) & \multirow{2}{*}{\multicolumn{2}{|c|}{$\begin{array}{l}32 \cdot 2 \\
77 \cdot 1\end{array}$}} & \multirow{2}{*}{\multicolumn{2}{|c|}{$\begin{array}{l}29.7 \\
77.2\end{array}$}} & \multirow{2}{*}{\multicolumn{2}{|c|}{$\begin{array}{l}23.6 \\
69.9\end{array}$}} & \multirow{2}{*}{\multicolumn{2}{|c|}{$\begin{array}{l}22 \cdot 4 \\
64.2\end{array}$}} & 0.005 \\
\hline Newly diagnosed dyslipidaemia (\%) & & & & & & & & & $<0.0001$ \\
\hline CVD risk factors ( $Z$ score) $t$ & 1.06 & 4.7 & 0.65 & 4.8 & -0.64 & $4 \cdot 3$ & -1.00 & 4.8 & $<0.0001$ \\
\hline
\end{tabular}

${ }^{*}$ For continuous characteristics, performed using one-way ANOVA. For categorical tests, the $\chi^{2}$ test for trend was used.

†CVD risk factor score was calculated as the sum of $Z$ scores for systolic blood pressure, diastolic blood pressure, waist circumference, BMI, fasting plasma glucose, total cholesterol, TAG, LDL-cholesterol and HDL-cholesterol. 
Table 3. Multivariate adjusted association between fruit and vegetable intake $(\mathrm{g} / \mathrm{d})$ and common cardiovascular risk factors ${ }^{\star}$ (Regression coefficients and $95 \%$ confidence intervals)

\begin{tabular}{|c|c|c|c|c|c|c|c|c|c|c|c|c|}
\hline & \multicolumn{12}{|c|}{ First quartile $v$. fourth quartile of fruit and vegetable intake $(\mathrm{g} / \mathrm{d}) \dagger$} \\
\hline & \multicolumn{3}{|c|}{ Model 1} & \multicolumn{3}{|c|}{ Model 2} & \multicolumn{3}{|c|}{ Model 3} & \multicolumn{3}{|c|}{ Model 4} \\
\hline & $\beta$ & $95 \% \mathrm{Cl}$ & $P$ & $\beta$ & $95 \% \mathrm{Cl}$ & $P$ & $\beta$ & $95 \% \mathrm{Cl}$ & $P$ & $\beta$ & $95 \% \mathrm{Cl}$ & $P$ \\
\hline $\begin{array}{l}\text { Systolic blood pressure } \\
(\mathrm{mmHg})\end{array}$ & $-5 \cdot 4$ & $-8.89,-1.94$ & 0.002 & -4.5 & $-7 \cdot 76,-1 \cdot 29$ & 0.006 & $-4 \cdot 6$ & $-7 \cdot 80,-1 \cdot 3$ & 0.006 & $-2 \cdot 6$ & $-5 \cdot 92,-1.02$ & 0.027 \\
\hline $\begin{array}{l}\text { Diastolic blood pressure } \\
\text { (mmHg) }\end{array}$ & -3.4 & $-5 \cdot 86,-1.48$ & $<0.0001$ & $-3 \cdot 2$ & $-5.33,-1.09$ & 0.003 & $-3 \cdot 2$ & $-5.35,-1.08$ & 0.003 & $-1 \cdot 6$ & $-3.80,0.530$ & 0.138 \\
\hline $\mathrm{BMI}\left(\mathrm{kg} / \mathrm{m}^{2}\right)$ & $-2 \cdot 0$ & $-2 \cdot 74,-1 \cdot 32$ & $<0.0001$ & $-2 \cdot 3$ & $-2.91,-1.52$ & $<0.0001$ & $-2 \cdot 3$ & $-2.96,-1.57$ & $<0.0001$ & - & - & - \\
\hline Waist circumference $(\mathrm{cm})$ & -7.9 & $-9.87,-5.96$ & $<0.0001$ & $-7 \cdot 6$ & $-9.58,-5.69$ & $<0.0001$ & -7.9 & $-9.73,-5.84$ & $<0.0001$ & $-2 \cdot 6$ & $-3.69,-1.46$ & $<0.0001$ \\
\hline $\begin{array}{l}\text { Fasting blood sugar } \\
(\mathrm{mg} / \mathrm{l})\end{array}$ & -36 & $-87 \cdot 5,15 \cdot 9$ & 0.175 & -31 & $-82 \cdot 9,21 \cdot 0$ & 0.242 & -32 & $-83 \cdot 9,20 \cdot 4$ & 0.231 & -19 & $-74 \cdot 0,34 \cdot 5$ & 0.474 \\
\hline $\begin{array}{l}\text { Serum total } \\
\text { cholesterol }(\mathrm{mg} / \mathrm{l})\end{array}$ & -77 & $-140 \cdot 3,-13 \cdot 0$ & 0.019 & -73 & $-134 \cdot 5,-11 \cdot 4$ & 0.020 & -75 & $-136 \cdot 6,-13 \cdot 3$ & 0.014 & -50 & $-113 \cdot 9,-13 \cdot 6$ & 0.017 \\
\hline Serum TAG $(\mathrm{mg} / \mathrm{l})$ & -131 & $-266 \cdot 4,5 \cdot 4$ & 0.060 & -114 & $-250 \cdot 1,21 \cdot 8$ & 0.100 & -118 & $-254 \cdot 3,19 \cdot 2$ & 0.092 & -45 & $-185 \cdot 6,95 \cdot 3$ & 0.527 \\
\hline LDL-cholesterol (mg/l) & -79 & $-134 \cdot 1,-24 \cdot 8$ & 0.004 & -77 & $-130 \cdot 6,-22 \cdot 5$ & 0.006 & -78 & $-132 \cdot 1,-23 \cdot 8$ & 0.014 & -55 & $-110 \cdot 8,-11 \cdot 1$ & 0.039 \\
\hline HDL-cholesterol (mg/l) & 29 & $10 \cdot 8,40 \cdot 7$ & 0.002 & 26 & $8 \cdot 8,44 \cdot 0$ & 0.003 & 27 & $8 \cdot 9,44 \cdot 3$ & 0.003 & 14 & $-4.4,31.6$ & 0.139 \\
\hline $\begin{array}{l}\text { CVD risk factors } \\
\text { (Z score }) \ddagger\end{array}$ & $-2 \cdot 7$ & $-3.59,-1.83$ & $<0.0001$ & $-2 \cdot 6$ & $-3 \cdot 42,-1 \cdot 75$ & $<0.0001$ & $-2 \cdot 6$ & $-3.5,-1.79$ & $<0.0001$ & -1.0 & $-1.74,-0.32$ & 0.004 \\
\hline
\end{tabular}

*All models were adjusted for total energy intake (kJ). Model 1 was unadjusted; model 2 was adjusted for age (years) and sex (dichotomous); model 3 was adjusted for model 2 and smoking (yes or no) and alcohol (yes or no); model 4 was adjusted for model 3 and BMI (continuous variable).

$\ddagger$ CVD risk factor score was calculated as the sum of $Z$ scores for systolic blood pressure, diastolic blood pressure, waist circumference, BMI, fasting plasma glucose, total cholesterol, TAG, LDL-cholesterol and HDL-cholesterol. 


\section{Discussion}

CVD is becoming the leading cause of mortality and morbidity in many developing countries, especially in India. Levels of various CVD risk factors are rising with the rapid nutritional and epidemiological transition in these countries as reflected by higher diabetes prevalence, increased cholesterol, blood pressure levels and greater obesity rates ${ }^{1}$. There is also increasing evidence that energy-dense foods usually associated with lower fruit and vegetable intake increase the risk of $\mathrm{CVD}^{19}$.

In the present cross-sectional study, a higher fruit and vegetable intake was inversely associated with several risk factors for CVD such as waist circumference, BMI, total cholesterol and LDL-cholesterol concentration, independent of age, sex, smoking status, alcohol, BMI and total energy intake. Overall fruit and vegetable intake explained $48 \%$ of the protective effect against CVD risk factors. To our knowledge, this is the first epidemiological study from India directly showing a link between decreasing fruit and vegetable intake individually with virtually all CVD disease risk factors.

Obesity, particularly abdominal obesity, is a well-known risk factor for CVD and type 2 diabetes; Asian Indians are known to have lower BMI than Europeans ${ }^{20}$. However, for any given BMI, Asian Indians have greater waist:hip ratios $^{20,21}$ and abdominal fat than Europeans. Studies suggest that a diet rich in dietary fibre is protective against obesity, as obesity is less common in populations that consume a high-fibre diet and more prevalent in populations that consume a low-fibre $\operatorname{diet}^{22}$. Although earlier studies from India have assessed the effect of dietary fat and obesity, limited data are available on the association of fruit and vegetable intake with obesity (including central obesity) in this population. In the present study, fruit and vegetable intake was inversely correlated to waist circumference and BMI and this is reflected in the lower CVD risk factor prevalence. Similar results were also reported in other epidemiological studies ${ }^{23}$. The mechanisms underlying such an effect are possibly due to high fibre intake, which further reduces the total energy intake and is associated with increased fat excretion ${ }^{24}$, improved insulin sensitivity and reduced insulinaemia ${ }^{23}$.

Diets rich in vegetables and fruits have been shown to control and prevent high blood pressure in a multicentre clinical trial with a heterogeneous population ${ }^{25}$. In the Chicago Western Electric Study, fruit and vegetable intake was inversely associated with an age-related rise in blood pressure ${ }^{26}$. In a cross-sectional study among 4393 individuals in Spain, a high fruit and vegetable intake was inversely associated with blood pressure ${ }^{27}$. Similar results were also reported in a cross-sectional study among 1497 individuals in Kerala, South India $^{28}$. This inverse relationship was also evident from the present study where the mean systolic blood pressure was $4.9 \mathrm{mmHg}$ and diastolic blood pressure $2.9 \mathrm{mmHg}$ lower for those with the highest consumption of fruit and vegetable intake. These findings suggest that the adoption of diets rich in fruits and vegetables might potentially shift the population distribution of blood pressure downward and thereby prevent CVD.

Serum total cholesterol and LDL-cholesterol are wellknown risk factors for $\mathrm{CVD}^{3}$. There is also evidence to show that diets rich in fruits and vegetables and low-fat dairy products and reduced in saturated fat, total fat and cholesterol content (dietary approaches to stop hypertension (DASH) diet) substantially lower the total and LDL-cholesterol concentration ${ }^{29}$. Fornes et al. ${ }^{30}$ reported in a cross-sectional study that the intake of fruits and vegetables was inversely correlated with LDL-cholesterol. Other investigators $^{31}$ also reported on the beneficial effect of fruit and vegetable intake on LDL-cholesterol concentration. The present findings are also consistent with these reports, as the levels of both total and LDL-cholesterol were lower in the higher quartiles of fruit and vegetable intake.

Viswanathan \& Mohan $^{32}$ showed significant reduction in serum cholesterol among diabetic patients with a high-carbohydrate, high-fibre diet and these effects were sustained for a long period of time ${ }^{33}$. Diets rich in fruits and vegetables are good sources of dietary fibre, which may indirectly lower serum cholesterol levels. In addition, antioxidants such as vitamin $C$ and $\beta$-carotene may help to reduce lipid oxidation of LDL-cholesterol, thereby preventing the development and progression of atherogenesis ${ }^{34-36}$.

Studies on dietary patterns test the hypothesis that a combination of foods and their nutrients, rather than the individual constituents of a diet, confers or reduces the disease risk. The biological mechanisms responsible for the beneficial effects of fruits and vegetables on CVD risk are therefore likely to be multiple. Besides their contribution to low energy, high fibre content and low glycaemic load, fruits and vegetables are also rich in phytochemicals, antioxidants and other micronutrients, all of which could be beneficial in reducing the risk of $\mathrm{CVD}^{37}$.

The $\mathrm{WHO}^{38}$ recommends a population goal of consumption of a minimum $400 \mathrm{~g}$ fruits and vegetables per $\mathrm{d}$ for the prevention of chronic non-communicable diseases. The mean intake of fruits and vegetables in the present study was $265 \mathrm{~g} / \mathrm{d}$, which was much lower than the recommended intake by the WHO. Though India has a prominent share in the global production of fruits and vegetables and a significant proportion of the population is vegetarian ${ }^{39}$, this does not seem to be reflected in an increase in the consumption of fruits and vegetables - perhaps the result of export and as it is not affordable by a large section of the population ${ }^{40}$. This might be one of the less-emphasised reasons for the increased susceptibility of Asian Indians to diabetes and premature $\mathrm{CVD}^{4,5,41}$.

One of the limitations of the study is that being a cross-sectional one, it is not the appropriate design to assess the cause and effect between diets and CVD. Longitudinal studies or clinical trials are best suited to evaluate the role of fruit and vegetables in the development of, or protection against, CVD and its risk factors. Physical activity was also not controlled in the present study, but could have, at least in part, been adjusted by adjusting for BMI and total energy intake.

The present study, however, has several strengths. We investigated the association in a relatively large population representative of the overall population of Chennai, which is in turn representative of urban India and hence the results can be extrapolated at least to urban India. The study used an FFQ, to measure the dietary intake of fruits and vegetables, which is considered a better method than a single $24 \mathrm{~h}$ recall or even a $7 \mathrm{~d}$ food record ${ }^{42}$. The FFQ used in the present study covered seasonality and has been validated and published ${ }^{18}$. In addition, CVD risk $Z$ score, which we used to define 
clustering of CVD risk factors on a continuous scale, is statistically more sensitive and less error prone compared with other approaches ${ }^{43}$. Finally, use of regression analysis in the present study allowed for simultaneous adjustment of several confounding variables. The present study thus offers valuable new data from India on the role of fruit and vegetable intake and the prevalence of CVD risk factors in a population at very high risk of CVD. Further epidemiological studies are needed to further elucidate the type and amount of fruit and vegetables that are most effective in the prevention of chronic diseases such as diabetes and CVD in South Asians in general and Asian Indians in particular.

\section{Acknowledgements}

We thank the Chennai Willington Corporate Foundation, Chennai for the CURES field studies. This is the forty-sixth publication from CURES.

\section{References}

1. Reddy KS \& Yusuf S (1998) Emerging epidemic of cardiovascular disease in developing countries. Circ J 97, 596-601.

2. Reddy KS \& Katan BM (2004) Diet, nutrition and the prevention of hypertension and cardiovascular diseases. Public Health Nutr 7, 167-186.

3. Enas EA, Yusuf S \& Mehta JL (1992) Prevalence of coronary artery diseases in Asian Indians. Am J Cardiology 70, 945-949.

4. Mohan V, Deepa R, Shanthirani S \& Premalatha G (2001) Prevalence of coronary artery disease and its relationship to lipids in a selected population in south India. The Chennai Urban Population Study (CUPS no. 5). J Am Coll Cardiol 38, 682-687.

5. Prabhakaran D, Shah P, Chaturvedi V, Ramakrishnan L, Manhapra A \& Reddy KS (2005) Cardiovascular risk factor prevalence among men in a large industry of northern India. Natl Med $J$ India 18, 59-65.

6. Bazzano LA (2004) Dietary Intake of Fruit and Vegetable Intake and Risk of Diabetes Mellitus and Cardiovascular Diseases. Joint FAO/WHO Workshop on Fruits and Vegetables for Health. Kobe, Japan, September 2004. Geneva: WHO.

7. Khaw KT \& Barrett-Connor E (1987) Dietary potassium and stroke associated mortality. A 12-year prospective population study. N Eng J Med 316, 235-240.

8. Knekt P, Reunanen A, Jarvinen R, Seppanen R, Heliovaara M \& Aromaa A (1994) Antioxidant vitamin intake and coronary mortality in a longitudinal population study. Am J Epidemiol 139, $1180-1189$.

9. Rimm EB, Ascherio A, Giovannucci E, Spiegelman D, Stamfer MJ \& Willett WC (1996) Vegetable, fruit, and cereal fibre intake and risk of coronary heart disease among men. JAMA 275, 447-451.

10. The World Health Report (2002) Reducing Risks, Promoting Healthy Lifestyles. Geneva: WHO.

11. Dauchet L, Amouyel P, Hercberg S \& Dallongeville J (2006) Fruit and vegetable consumption and risk of coronary heart disease: a meta-analysis of cohort studies. Fruit and vegetable consumption and risk of coronary heart disease: a meta-analysis of cohort studies. J Nutr 136, 2588-2593.

12. Law MR \& Morris KJ (1998) By how much does fruit and vegetable consumption reduce the risk of ischaemic heart disease? Eur J Clin Nutr 52, 549-556.
13. Rimm EB, Ascherio A, Giovannucci E, Stampfer M \& Willett W (1997) Dietary fibre intake and risk of coronary heart disease among a large population of US men. Am J Epidemiol 26, $1-13$.

14. Deepa M, Pradeepa R, Rema M, Anjana M, Deepa R, Shanthirani S \& Mohan V (2003) The Chennai Urban Rural Epidemiology Study (CURES) - study design and methodology (urban component) (CURES-I). J Assoc Phys India 51, 863-870.

15. Alberti KG \& Zimmet PZ (1998) Definition diagnosis and classification of diabetes mellitus and its complications. Part 1, Diagnosis and classification of diabetes mellitus, provisional report of a WHO consultation. Diabet Med 15, $539-553$

16. Chobanian AV, Bakris GL, Black HR, et al. (2003) The seventh report of the Joint National Committee on Prevention, Detection, Evaluation and Treatment of High Blood Pressure: the JNC-7 report. JAMA 289, 2560-2572.

17. Expert Panel on Detection, Evaluation, and Treatment of High Blood Cholesterol in Adults (2001) Executive summary of the third report of the Detection, Evaluation, and Treatment of High Blood Cholesterol in Adults (Adult Treatment Panel III). JAMA 285, 2486-2497.

18. Sudha V, Radhika G, Sathya RM, Ganesan A \& Mohan V (2006) Reproducibility and validity of an interviewer-administered semi-quantitative food frequency questionnaire to assess dietary intake of urban adults in Southern India. Int $J$ Food Sci Nutr 57, 481-493.

19. Hu FB (2003) Plant-based foods and prevention of cardiovascular disease: an overview. Am J Clin Nutr 78, Suppl. 3, 544S-551S.

20. Raji A, Seely EW, Arky RA \& Siminson DC (2001) Body fat distribution and insulin resistance in healthy Asian Indians and Caucasians. J Clin Endocrinol Metab 86, 5366-5371.

21. Ramachandran A, Snehalatha C, Viswanathan V, Viswanathan M \& Haffner SM (1997) Risk of non-insulin dependent diabetes mellitus conferred by obesity and central adiposity in different ethnic groups: a comparative analysis between Asian Indians, Mexican Americans and Whites. Diabetes Res Clin Pract 36, $121-125$

22. Van Itallie TB (1978) Dietary fibre and obesity. Am J Clin Nutr 31, Suppl. 10, S43-S52.

23. Ludwig DS, Pereira MA, Kroenka P, Hilner JE, Van Horn L, Slattery ML \& Jacobs DR (1999) Dietary fibre, weight gain and cardiovascular disease risk factors in young adults. JAMA 282, 1539-1546.

24. Cara L, Dubois C, Borel P, Armand M, Senft M, Portugal H, Pauli A-M, Bernard P-M \& Lairon D (2002) Effects of oat bran, rice bran, and wheat fibre and wheat germ on postprandial lipemia in healthy adults. Am J Clin Nutr 76, 390-398.

25. Appel LJ, Moore TJ, Obarzanek E, et al. (1997) A clinical trial of the effects of dietary patterns on blood pressure. DASH Collaborative Research Group. N Engl J Med 336, 1117-1124.

26. Miura K, Greenland P, Stamler J, Liu K, Daviglus ML \& Nakagawa H (2004) Relation of vegetable, fruit and meat intake to 7-year blood pressure change in middle-aged men: the Chicago Western Electric study. Am J Clin Nutr 159, $572-580$.

27. Alonsa A, de la Fuente C, Martín-Arnau AM, de Irala J, Martínez JA \& Martinez-González MA (2004) Fruit and vegetable consumption is inversely associated with blood pressure in a Mediterranean population with a high vegetable-fat intake: the Seguimiento Universidad de Navarra (SUN) study. Br J Nutr 92, 311-319.

28. Beegom R \& Singh RB (1997) Association of higher saturated fat intake with higher risk of hypertension in an urban population of Trivandrum in South India. Int J Cardiol 58, $63-70$. 
29. Obarzanek E, Sacks FM, Vollmer WM, et al. (2001) DASH Research Group. Effects on blood lipids of a blood pressure lowering diet: the Dietary Approaches to Stop Hypertension (DASH) trial. Am J Clin Nutr 74, 80-89.

30. Fornes NS, Marins IS, Hernan M, Velasquez-Melendex G \& Ascherio A (2000) Frequency of food consumption and lipoprotein serum levels in the population of an urban area, Brazil. Rev Saude Publica 34, 380-387.

31. Bruce B, Spiller GA, Klevay LM \& Gallagher SK (2000) A diet high in whole and unrefined foods favorably alter lipids, antioxidant defenses, and colon function. J Am Coll Nutr 19, 61-67.

32. Viswanathan M \& Mohan V (1991) Dietary management of Indian vegetarian diabetics. Bull Nutr Found India 12, 1-3.

33. Viswanathan M, Ramachandran A, Mohan V \& Snehalatha C (1981) High carbohydrate diet, high fibre diet in diabetes. J Diab Assoc India 21, 90-96.

34. Lairon D (1996) Dietary fibres: effects on lipid metabolism and mechanism of action. Eur J Clin Nutr 50, 125-133.

35. Brown L, Rosner B, Willett W \& Sacks FM (1999) Cholesterollowering effects of dietary fibre: a meta analysis. Am J Clin Nutr 69, 30-42.

36. McKeown NM, Meigs JB, Liu S, Wilson PW \& Jacques PF (2002) Whole grain intake is favorably associated with metabolic risk factors for type 2 diabetes and cardiovascular disease in the Framingham Offspring Study. Am $J$ Clin Nutr 76, $390-398$.

37. Joshipura JK, Hu FB, Manson JE, et al. (2001) The effect of fruit and vegetable intake on risk of coronary heart diseases. Ann Intern Med 134, 1106-1114.

38. World Health Organization (2003) Diet, Nutrition and the Prevention of Chronic Diseases. Joint WHO/FAO Expert Consultation. WHO Technical Report Series. no. 916. Geneva: WHO.

39. Kaul GL (1998) Fruit and vegetable production in India. NFI Bull 19, 5-8.

40. Shetty PS (2002) Nutrition transition in India. Public Health Nutr 5, 175-182.

41. Mohan V, Shanthirani CS \& Deepa R (2003) Glucose intolerance (diabetes and IGT) in a selected south Indian population with special reference to family history, obesity and lifestyle factors - The Chennai Urban Population Study (CUPS 14). JAPI 51, 771-777.

42. Willett W (1998) Nutritional Epidemiology Monographs in Epidemiology and Biostatistics, vol. 30. Oxford: Oxford University Press.

43. Ragland DR (1992) Dichotomizing continuous outcome variables: dependence of the magnitude of association and statistical power on the cutpoint. Epidemiology 3, 434-440. 